\title{
Types of Evidence and Routes to Persuasion: The Unimodel Versus Dual-Process Models
}

\author{
Howard Lavine \\ Department of Political Science \\ State University of New York at Stony Brook
}

Following the pioneering research of Hovland and his colleagues in the 1950s (e.g., Hovland \& Janis, 1959; Hovland, Janis, \& Kelley, 1953; Hovland, Lumsdaine, \& Sheffield, 1949), social psychologists have proposed a variety of specific "process" models of persuasion to explain how the plethora of source, message, recipient, and context factors produce changes in attitude (for reviews, see Eagly \& Chaiken, 1993; Petty \& Wegener, 1998). Most investigators, however, would seem to accept the more general proposition that persuasion can occur through one of two qualitatively different "routes." Both Petty and Cacioppo's (1986) Elaboration Likelihood Model (ELM) and Chaiken's (1987; Chaiken, Liberman, \& Eagly, 1989) Heuristic Systematic Model (HSM) distinguish between persuasion based on careful scrutiny of the merits of the message arguments and persuasion that results from the processing of any of a variety of nonmessage factors such as source cues. The distinction between cues and heuristics and message arguments is fundamental in dual-process models of persuasion, for these two categories of variables covary (in prior research; e.g., Petty, Cacioppo, \& Goldman, 1981) with several factors that mediate persuasive outcomes (e.g., information length, complexity, accessibility, order of presentation, and relevance). Moreover, dual-process models imply that levels of motivation and ability determine whether persuasion is mediated by cues and heuristics or by message arguments, which in turn determines the extent to which postmessage attitudes are enduring and consequential (e.g., Petty \& Cacioppo, 1986; Petty, Haugtvedt, \& Smith, 1995).

More specifically, in the dual-process literature there is an implied relation between the amount of thinking the recipient engages in and the object(s) on which that thought is projected (e.g., message arguments, source characteristics). "Deeper," more effortful thinking occurs when considering the cogency of the message arguments, whereas "shallow" or less effortful thinking occurs in relation to nonmessage features of the persuasion situation. Underlying this implicit covariation between content and process is the assumption that cues and heuristics and message arguments importantly differ in terms of such persuasion-relevant factors as informational length, complexity, and relevance. Because message arguments are thought to be (or at least are typically operationalized as) longer, more complex, and more relevant to persuasive conclusions than cues and heuristics, persuasion based on the former is believed to (a) require higher levels of processing motivation and ability, (b) confer more judgmental confidence, and (c) produce more consequential (i.e., stronger) attitudes than persuasion based on the latter. Although some of these differences between cues and heuristics and message arguments have not been directly tested (e.g., whether message arguments are inherently longer and more complex than cues and heuristics), there is ample support for many of these distinctions in the ELM and HSM literatures (e.g., the differential impact of motivation and ability on the processing of cues and heuristics and message arguments).

Kruglanski and Thompson's provocative article represents a fundamental challenge to this dual-process conceptualization of the persuasion process. There are two important aspects to their claim: First, they argue that in most ELM and HSM studies, the cue-message distinction has been inadvertently confounded with key persuasion parameters such as length, complexity, order of entry, and relevance. They argue that this chronic conflation in prior research is responsible for both the differential impact of motivation and ability on the processing of cues and heuristics versus message arguments (e.g., Petty et al., 1981), and for the finding that persuasion based on message arguments yields stronger attitudes than persuasion based on cues and heuristics (for a review, see Petty et al., 1995).

Kruglanski and Thompson argue that persuasion is mediated by the quality of the processed information-its length, complexity, relevance, accessibility, and so forth-and not whether its contents happen to be cues and heuristics or message arguments. Specifically, Kruglanski and Thompson argue that difficult-to-process information (of either the cue or heuristic or message argument type) mediates persuasive outcomes when motivation and ability are high and that easy-to-process information (of either type) will prevail under low motivation or ability conditions. Similarly, they propose that strength-related outcomes (i.e., an attitude's persistence over time, its resistance to change, and its relation to behavior) depend not on whether the information is cue- or argument-based, but on the depth and extensiveness of the recipient's processing. In sum, Kruglanski and Thompson contend that the ostensible cue-message effects observed in dual-process studies are epiphenomenal. 
Their second claim nullifies the cue-message distinction at the level of process. According to the unimodel, persuasion (and knowledge formation more generally) occurs through a syllogistic reasoning process in which both cues and arguments may serve as "evidence" (the syllogism's minor premise). Attitude change occurs when the presence of evidence is combined with a conditional belief linking it to a conclusion (the major premise). The notion that persuasion occurs when message recipients recognize the relations among logically related beliefs (and adjust their attitudes accordingly) is fundamentally similar to McGuire's (1960, 1981) probabilogical model and Wyer's (1970; Wyer \& Hartwick, 1980) conditional inference model. Because Kruglanski and Thompson view the syllogistic reasoning process underlying cueand argument-based persuasion to be similar in kind, the unimodel would seem to be at odds with the ELM and HSM proposition that persuasion can be mediated by qualitatively different processing routes.

To evaluate the potential value of the unimodel, it is imperative to: (a) assess the extent and nature of its conceptual differences with the ELM and the HSM, (b) determine whether its predictions are in fact fundamentally different from these earlier models, and (c) identify the sorts of experiments that could provide more powerful critical tests of the propositions of single- versus dual-process models. The question of whether the differences between the unimodel and its dual-process counterparts are merely a matter of semantics or are of real substance largely turns on the hypothesized relation between processing mode (central/systematic vs. peripheral/heuristic) and information type (message arguments vs. cues and heuristics). My understanding of the HSM (Chaiken et al., 1989; Eagly \& Chaiken, 1993) is that the systematic mode is primarily based on the processing of message arguments and that the heuristic mode is based on the processing of nonmessage factors (e.g., heuristic cues, schemata) present in the persuasion situation. For example, Chaiken et al. (1989) stated that

When engaged in systematic processing, people judge the validity of a message's advocated position by scrutinizing all relevant information (especially persuasive argumentation) and by thinking about this information in relation to other knowledge they may possess about the object or issue discussed in the message. (p. 215, italics added)

"When processing heuristically, people focus on that subset of available information that enables them to use simple inferential rules, schemata, or cognitive heuristics to formulate their judgments and decisions" (Chaiken et al., 1989, p. 214). Within the HSM, the processing mode-information type (cues and heuristics vs. arguments) connection is based on the idea that high levels of motivation increase desired judgmental confidence and that message arguments can facilitate confidence more so than can heuristic cues (see also Petty, 1994). ${ }^{1}$

Clearly, this aspect of the HSM is in conflict with Kruglanski and Thompson's contention that processing effort and information type are theoretically orthogonal. According to the unimodel, high levels of motivation and ability should induce relatively extensive processing of whatever information is viewed as most relevant to the judgment at hand. Although the data presented by Kruglanski and Thompson (especially Studies 3 and 4) provide some evidence for this, a stronger test of this central unimodel hypothesis would involve varying information length (and, in additional experiments, complexity, and relevance) and motivation to process along with both a cue and a message quality manipulation. If systematic/central processing is mediated by recipients' cognitive responses in relation to the message arguments, and if peripheral/heuristic processing is mediated by the influence of cues and heuristics, the data should yield the familiar Motivation $\times$ Argument Quality and Motivation $\times$ Cue Type interactions (e.g., Petty et al., 1981). If, however, motivation level determines whether recipients process short or long (or easy or complex) information, and not whether the information consists of cues or arguments, three-way Motivation $\times$ Argument Quality $\times$ Information Length and Motivation $\times$ Cue Type $\times$ Information Length interactions should be obtained. Specifically, highly motivated recipients should distinguish between both expert and novice source cues (for example) and strong and weak arguments when the information is lengthy (or complex), whereas relatively unmotivated recipients should distinguish between cue types and argument quality when the information is short (or simple).

Finally, because attitudes vary widely in their durability and impact (e.g., Lavine, Huff, Wagner, \& Sweeney, 1998; Petty \& Krosnick, 1995), it is important to determine whether attitudes formed or changed on the basis of cues and heuristics versus persuasive arguments differ in their stability over time, resistance to change, and influence on judgments and behavior. This is perhaps the most critical area in which to test

\footnotetext{
${ }^{1}$ The hypothesized relation between processing mode (central vs. peripheral) and information type (message arguments vs. cues and heuristics) is less clear in the ELM. For example, Petty and Wegener (1998) noted that when the elaboration likelihood is low, attitude change can be based on a "less effortful (less careful) examination of the same information" as when the elaboration likelihood is high (p. 327). However, Petty and Wegener also noted that "when personal relevance is high, people are more influenced by their processing of the substantive arguments in a message and are less impacted by peripheral processes" (p. 328). This ostensible confusion is largely based on the fact that arguments contained more complex and lengthy information than did cues and heuristics in prior research (e.g., Petty, Cacioppo, \& Goldman, 1981).
} 
Kruglanski and Thompson's functional equivalence argument. According to the unimodel, a newly changed attitude's strength should depend entirely on the quality of the information that is processed (i.e., its complexity, length, relevance). If, as the authors argue, cues and heuristics and message arguments do not systematically vary on such dimensions, there is little reason to believe that cue- and argument-based persuasion would produce differentially strong attitudes. However, dual-process theorists ascribe the strength-related consequences of elaboration to the unique cognitive processes involved in the processing of message arguments. Specifically, Petty et al. (1995; Petty \& Cacioppo, 1986) hypothesized that the processing of arguments causes message recipients to access their prior attitude-relevant beliefs and knowledge much more so than does the processing of cues and heuristics. This repeated accessing of the prior attitude structure should foster greater integration of new and old attitude-relevant information, and in doing so increase the accessibility and internal consistency of attitude-related beliefs and feelings. To the extent that argument-based processing does in fact produce such structural alterations, attitudes that receive this type of processing should last longer and therefore be more predictive of behavior than attitude change mediated by cue-based processes (see Doll \& Ajzen, 1992; Eagly \& Chaiken, 1995).

Our understanding of persuasion processes would greatly profit from directly evaluating the extent to which attitude persistence, resistance, and consistency with behavior are driven by elaboration per se (as the unimodel suggests) or the elaboration of message arguments (as the dual-process models would seem to suggest). This can be accomplished with the Motivation (or Ability) $\times$ Information Length $\times$ Cue Type $\times$ Argument Quality design described earlier. The potential mediating roles of strength-related attitude properties such as evaluative-cognitive consistency (Chaiken, Pomerantz, \& Giner-Sorolla, 1995), accessibility (Fazio, 1995), and attitude importance (Boninger, Krosnick, Berent, \& Fabrigar, 1995; Thomsen, Borgida, \& Lavine, 1995) should also be directly assessed (e.g., Petty et al., 1995). The importance of the message-cue distinction in persuasion may well depend on whether the processing of message arguments produces attitudes that are more accessible, important, and internally consistent than those based on the processing of equally relevant, complex, and lengthy cues and heuristics.

In sum, Kruglanski and Thompson raise interesting and important questions about the nature of the persuasion process. Their reinterpretation of the manifest interactions produced under the auspices of dual-process models makes clear that persuasion researchers should attempt to experimentally separate qualities of the persuasive information (e.g., length, complexity, rele- vance) from the type of information (i.e., arguments vs. cue/heuristics) processed. By disentangling and orthogonally manipulating these factors and by directly measuring mediating processes (Petty et al., 1995), social psychologists stand to build on the important insights generated by the dual-process theorists (e.g., Chaiken et al., 1989; Petty \& Cacioppo, 1986).

\section{Note}

Howard Lavine, Department of Political Science, State University of New York at Stony Brook, Stony Brook, NY 11794. E-mail: Hlavine@datalab2. sbs.sunysb.edu

\section{References}

Boninger, D. S., Krosnick, J. A., Berent, M. K., \& Fabrigar, L. R. (1995). The causes and consequences of attitude importance. In R. E. Petty \& J. A. Krosnick (Eds.), Attitude strength: Antecedents and consequences (pp. 159-190). Mahwah, NJ: Lawrence Erlbaum Associates, Inc.

Chaiken, S. (1987). The heuristic model of persuasion. In M. P. Zanna, J. M. Olson, \& C. P. Herman (Eds.), Social influence: The Ontario symposium (Vol. 5, pp. 3-39). Hillsdale, NJ: Lawrence Erlbaum Associates, Inc.

Chaiken, S., Liberman, A., \& Eagly, A. H. (1989). Heuristic and systematic information processing within and beyond the persuasion context. In J. S. Uleman \& J. A. Bargh (Eds.), Unintended thought (pp. 212-252). New York: Guilford.

Chaiken, S., Pomerantz, E. M., \& Giner-Sorolla, R. (1995). Structural consistency and attitude strength. In R. E. Petty \& J. A. Krosnick (Eds.), Attitude strength: Antecedents and consequences (pp. 387-412). Mahwah, NJ: Lawrence Erlbaum Associates, Inc.

Doll, J., \& Ajzen, I. (1992). Accessibility and stability of predictors in the theory of planned behavior. Journal of Personality and Social Psychology, 63, 754-765.

Eagly, A. H., \& Chaiken, S. (1993). The psychology of attitudes. New York: McGraw-Hill.

Eagly, A. H., \& Chaiken, S. (1995). Attitude strength, attitude structure, and resistance to change. In R. E. Petty \& J. A. Krosnick (Eds.), Attitude strength: Antecedents and consequences (pp. 413-432). Mahwah, NJ: Lawrence Erlbaum Associates, Inc.

Fazio, R. H. (1995). Attitudes as object-evaluation associations: Determinants, consequences, and correlates of attitude accessibility. In R. E. Petty \& J. A. Krosnick (Eds.), Attitude strength: Antecedents and consequences (pp. 247-282). Mahwah, NJ: Lawrence Erlbaum Associates, Inc.

Hovland, C. I., \& Janis, I. L. (Eds). (1959). Personality and persuasibility. New Haven, CT: Yale University Press.

Hovland, C. I., Janis, I. L., \& Kelley, H. H. (1953). Communication and persuasion: Psychological studies of opinion change. New Haven, CT: Yale University Press.

Hovland, C. I., Lumsdaine, A. A., \& Sheffield, F. D. (1949). Experiments on mass communication. Princeton, NJ: Princeton University Press.

Lavine, H., Huff, J. W., Wagner, S. H., \& Sweeney, D. (1998). The moderating influence of attitude strength on the susceptibility to context effects in attitude surveys. Journal of Personality and Social Psychology, 75, 359-373. 
McGuire, W. J. (1960). Cognitive consistency and attitude change. Journal of Abnormal and Social Psychology, 60, 345-353.

McGuire, W. J. (1981). The probabilogical model of cognitive structure and attitude change. In R. E. Petty, T. M. Ostrom, \& T. C. Brock (Eds.), Cognitive responses in persuasion (pp. 291-307). Hillsdale, NJ: Lawrence Erlbaum Associates, Inc.

Petty, R. E. (1994). Two routes to persuasion: State of the art. In G. d'Ydewalle, P. Eelen, \& P. Berteleson (Eds.), International perspectives on psychological science (Vol. 2, pp. 229-247). Hillsdale, NJ: Lawrence Erlbaum Associates, Inc.

Petty, R. E., \& Cacioppo, J. T. (1986). The elaboration likelihood model of persuasion. In L. Berkowitz (Ed.), Advances in experimental social psychology (Vol. 19, pp. 123-205). San Diego, CA: Academic.

Petty, R. E., Cacioppo, J. T., \& Goldman, R. (1981). Personal involvement as a determinant of argument-based persuasion. Journal of Personality and Social Psychology, 41, 847-855.

Petty, R. E., Haugtvedt, C. P., \& Smith, S. M. (1995). Elaboration as a determinant of attitude strength: Creating attitudes that are persistent, resistant, and predictive of behavior. In R. E. Petty \& J. A. Krosnick (Eds.), Attitude strength: Antecedents and conse- quences (pp. 93-130). Mahwah, NJ: Lawrence Erlbaum Associates, Inc.

Petty, R. E., \& Krosnick, J. A. (Eds.). (1995). Attitude strength: Antecedents and consequences. Mahwah, NJ: Lawrence Erlbaum Associates, Inc.

Petty, R. E., \& Wegener, D. T. (1998). Attitude change: Multiple roles for persuasion variables. In D. T. Gilbert, S. T. Fiske, \& G. Lindzey (Eds.), The handbook of social psychology (4th ed., Vol. 1, pp. 323-390). New York: McGraw-Hill.

Thomsen, C. J., Borgida, E., \& Lavine, H. (1995). The causes and consequences of personal involvement. In R. E. Petty \& J. A. Krosnick (Eds.), Attitude strength: Antecedents and consequences (pp. 191-214). Mahwah, NJ: Lawrence Erlbaum Associates, Inc.

Wyer, R. S., Jr. (1970). Quantitative prediction of belief and opinion change: A further test of a subjective probability model. Journal of Personality and Social Psychology, 16, 559-570.

Wyer, R. S., Jr., \& Hartwick, J. (1980). The role of information retrieval and conditional inference processes in belief formation and change. In L. Berkowitz (Ed.), Advances in experimental social psychology (Vol. 13, pp. 241-284). San Diego, CA: Academic. 
Copyright of Psychological Inquiry is the property of Lawrence Erlbaum Associates and its content may not be copied or emailed to multiple sites or posted to a listserv without the copyright holder's express written permission. However, users may print, download, or email articles for individual use. 